\section{Commentary: Thoracic surgery in COVID-19 patients is not a taboo: A change of mind and correct timing are essential in COVID-19 surgical complications management}

\author{
Marco Scarci, MD, FRCS(Eng), FCCP, FACS, and \\ Federico Raveglia, MD
}

In the last 10 months, with the pandemic advent, thoracic surgeons were forced to split their attention between patients with complications from COVID-19 infection and urgent oncologic cases. The most striking challenge, especially at the beginning of the emergency, was that as hospitals' COVID-19 population increased and resources were stretched thin, surgeons were faced with the need to also provide care for respiratory complications in an unfamiliar infective environment. ${ }^{1}$ At the same time, it also has been shown that the development of symptomatic COVID-19 during the postoperative period is a dramatic event highly correlated with death. ${ }^{2}$ Therefore, surgeons have had to bear the brunt of the infection on multiple fronts: dealing with respiratory complications in both medical patients and patients who underwent lung cancer resection. Our area, the Lombardy region, was the most affected in Europe during the first wave, and indeed we were faced with 6 deaths among 12 patients who developed COVID-19 in the postoperative period for lung cancer, as well as many complications in ventilated and nonventilated patients (pneumothorax with ongoing air leak, empyema, chest wall hematoma, and

\footnotetext{
From the Department of Thoracic Surgery, Azienda Socio Sanitaria Territoriale Monza, San Gerardo Hospital, Monza, Italy.

Disclosures: The authors reported no conflicts of interest.

The Journal policy requires editors and reviewers to disclose conflicts of interest and to decline handling or reviewing manuscripts for which they may have a conflict of interest. The editors and reviewers of this article have no conflicts of interest.

Received for publication Jan 27, 2021; revisions received Jan 27, 2021; accepted for publication Jan 27, 2021; available ahead of print Feb 4, 2021.

Address for reprints: Marco Scarci, MD, FRCS(Eng), FCCP, FACS, ASST Monza, Via Pergolesi 33, 20900 Monza, Italy (E-mail: marco.scarci@mac.com).

J Thorac Cardiovasc Surg 2021;162:1665-6

$0022-5223 / \$ 36.00$

Copyright (c) 2021 by The American Association for Thoracic Surgery

https://doi.org/10.1016/j.jtcvs.2021.01.121
}

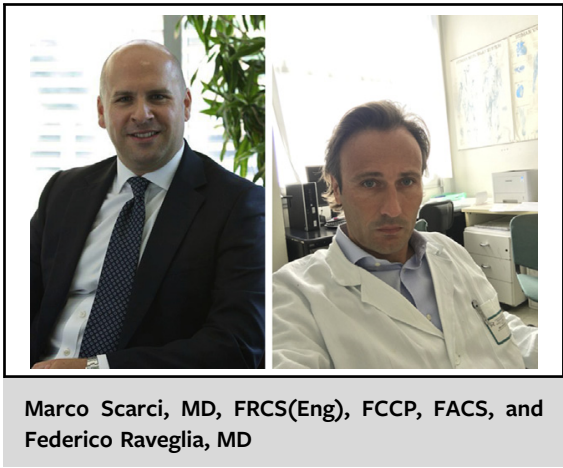

CENTRAL MESSAGE

In selected patients with

COVID-19 complications, surgery

is feasible with good outcomes.

Delaying necessary surgery

because of the potential infective

risk can result in a missed win-

dow of opportunity.

pneumatocele) and an high proportion (approximately $20 \%$ ) of infected healthcare providers.

Unfortunately, at the beginning of the pandemic, poor understanding of the actual outcomes of surgery in infected patients encouraged a conservative rather than an operative approach.

Compared with most of the current literature, the strength of the article by Chang and colleagues ${ }^{3}$ in this issue of the Journal is in identifying a pattern of conditions strictly related to COVID-19 that necessitate early thoracic surgery, identifying likely outcomes, and quantifying the risk of developing infection in healthcare providers. Their series of 13 COVID-19 cases with complex situations consisted of severe pneumothorax, spontaneous hemothorax, pneumatocele, and empyema. But what matters most are the authors' brilliant outcomes-77\% survival and $69 \%$ of cases discharged-suggesting that COVID-19 is not absolute contraindication to surgery. Our experience is similar; indeed, we did not register any infections among surgical staff, and all patients treated for complications of symptomatic COVID-19 were discharged to home except 1 patient with pneumonectomy who was in intensive care for severe pneumonia and sepsis at the time of this report. Notably, this patient was referred to us when this patient's general condition had already worsened and extracorporeal membrane 
oxygenation had been provided, reinforcing the idea that early referral and treatment of complications is advantageous for patients. In our opinion, this is the real key point of the article: as the authors show, thoracic surgery is feasible for patients with COVID-19 and selected complications, but correct timing is mandatory. These patients are usually in poor general condition because of a prolonged COVID-19 course; therefore, at the onset of any complications potentially requiring surgery, this should be promptly considered without further delay owing to the potential infective risk, especially given the authors' demonstration of very limited risk with correct use of protective personal equipment.

\section{References}

1. Scarci M, Raveglia F. Commentary: the double responsibility of the thoracic surgeon at the time of the pandemic: a perspective from the North of Italy. J Thorac Cardiovasc Surg. 2020;160:595-6.

2. Peng S, Huang L, Zhao B, Zhou S, Braithwaite I, Zhang N, et al. Clinical course of coronavirus disease 2019 in 11 patients after thoracic surgery and challenges in diagnosis. J Thorac Cardiovasc Surg. 2020;160:585-92.e2.

3. Chang SH, Chen D, Paone D, Geraci TC, Scheinerman J, Bizekis C, et al. Thoracic surgery outcomes for patients with Coronavirus Disease 2019. J Thorac Cardiovasc Surg. 2021;162:1654-64.
See Article page 1654 .

\section{Commentary: Coronavirus disease 2019 (COVID-19) and the thoracic surgeon: Choose wisely and preserve good judgment}

\author{
Richard Lazzaro, MD, FACS, Byron Patton, MD, and \\ Matthew L. Inra, MD
}

Since January 20, 2020, when the first patient in the United States was diagnosed with coronavirus disease 2019 (COVID-19), the United States and health care providers have treated, protected themselves from, adapted to, and learned from the virus that has caused the most significant pandemic of our generation. The pathophysiology of COVID-19 infection and its sequelae has not only required the expertise of internal medicine specialists, but all specialists.

The experience presented by Chang and colleagues ${ }^{1}$ describes surgical outcomes of a selected group of patients who had developed complications requiring thoracic surgery. The authors are to be lauded for their work operating,

From the Department of Cardiothoracic Surgery, Lenox Hill Hospital, New York, NY. Disclosures: The authors reported no conflicts of interest.

The Journal policy requires editors and reviewers to disclose conflicts of interest and to decline handling or reviewing manuscripts for which they may have a conflict of interest. The editors and reviewers of this article have no conflicts of interest.

Received for publication Jan 25, 2021; revisions received Jan 25, 2021; accepted for publication Jan 26, 2021; available ahead of print Feb 2, 2021.

Address for reprints: Richard Lazzaro, MD, FACS, Department of Cardiothoracic Surgery, Lenox Hill Hospital, 130 E 77th St, New York, NY 10075 (E-mail: rlazzaro@northwell1.edu).

J Thorac Cardiovasc Surg 2021;162:1666-7

$0022-5223 / \$ 36.00$

Copyright (c) 2021 by The American Association for Thoracic Surgery

https://doi.org/10.1016/j.jtcvs.2021.01.109

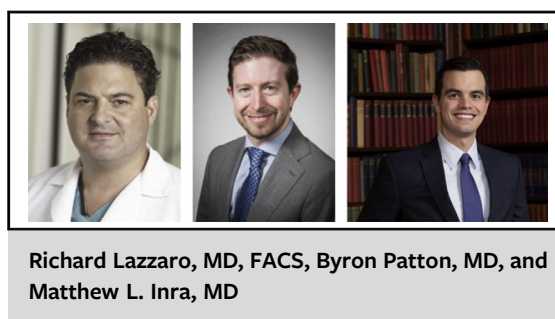

CENTRAL MESSAGE

Sound surgical judgment, patient

selection, and operative

technique are imperative to

operate safely on patients with

COVID-19.

healing, and protecting the team. The authors have made an important contribution to the literature, having demonstrated that thoracic surgery can be performed safely on patients positive for COVID-19. We must also remember to stringently assess the risks and benefits of surgery. Some "patients were in progressive respiratory distress that would have resulted in death without surgical intervention," but did surgical intervention hasten this inevitable outcome? Not all "Hail Mary" passes travel 48 yards with 6 seconds left and result in victory. Predetermining futility is difficult; the decision to proceed with surgery is associated with high 